Check for updates

Cite this: RSC Adv., 2017, 7, 50663

Received 7th September 2017

Accepted 18th October 2017

DOI: $10.1039 / c 7 r a 09959 b$

rsc.li/rsc-advances

\title{
Reactive molecular dynamics study of the decomposition mechanism of the environmentally friendly insulating medium $\mathrm{C}_{3} \mathrm{~F}_{7} \mathrm{CN} \uparrow$
}

\author{
Xiaoxing Zhang, (D) ${ }^{a}$ Yi Li, (D) ${ }^{a}$ Dachang Chen, ${ }^{a}$ Song Xiao, ${ }^{* a}$ Shuangshuang Tian, ${ }^{a}$ \\ Ju Tang and Ran Zhuo ${ }^{\mathrm{b}}$
}

\begin{abstract}
The extensive use of sulfur hexafluoride $\left(\mathrm{SF}_{6}\right)$ gas in the power industry has a strong greenhouse effect. Hence, many scholars are committed to studying $\mathrm{SF}_{6}$ alternative gases to achieve green power development. In the past two years, $\mathrm{C}_{3} \mathrm{~F}_{7} \mathrm{CN}$ (heptafluoroisobutyronitrile) has attracted the attention of many scholars due to its excellent insulation and environmental protection characteristics as a potential alternative gas. This study theoretically explores the decomposition characteristics of $\mathrm{C}_{3} \mathrm{~F}_{7} \mathrm{CN}$ and the $\mathrm{C}_{3} \mathrm{~F}_{7} \mathrm{CN} / \mathrm{CO}_{2}$ gas mixture based on the reactive molecular dynamics method and density functional theory. The main decomposition pathways of $\mathrm{C}_{3} \mathrm{~F}_{7} \mathrm{CN}$ and the enthalpy of each path at different temperatures were analyzed. The yield of the main decomposition products was obtained under several temperature conditions. The decomposition of $\mathrm{C}_{3} \mathrm{~F}_{7} \mathrm{CN}$ mainly produced $\mathrm{CF}_{3}, \mathrm{C}_{3} \mathrm{~F}_{7}, \mathrm{CN}, \mathrm{CNF}, \mathrm{CF}_{2}, \mathrm{CF}, \mathrm{F}$, and other free radicals and a few molecular products, such as $\mathrm{CF}_{4}$ and $\mathrm{C}_{3} \mathrm{~F}_{8}$. The $\mathrm{C}_{3} \mathrm{~F}_{7} \mathrm{CNN}_{2} \mathrm{CO}_{2}$ gas mixture has more excellent decomposition characteristics than that of the pure $\mathrm{C}_{3} \mathrm{~F}_{7} \mathrm{CN}$. The addition of $\mathrm{CO}_{2}$ effectively ensures that the gas mixture has a low liquefaction temperature, which is considerably suitable for use as a gas insulation medium. The relevant research results provide guidance for the further exploration on the electrical properties and practical engineering application of the $\mathrm{C}_{3} \mathrm{~F}_{7} \mathrm{CN}$ gas mixture.
\end{abstract}

\section{Introduction}

$\mathrm{SF}_{6}$ (sulfur hexafluoride) is the most common insulation medium used in high-voltage (HV) electrical equipment such as gas insulated switchgear (GIS). ${ }^{1}$ However, $\mathrm{SF}_{6}$ is a greenhouse gas (GHG) regulated under the Kyoto Protocol with a global warming potential (GWP) of $22800 .^{2,3}$ Although the proportion of greenhouse effect caused by the use of $\mathrm{SF}_{6}$ is not as large as the amount of fossil fuel energy consumed, the global atmospheric content of $\mathrm{SF}_{6}$ has increased by $20 \%$ in the past five years and the atmospheric mole fraction of $\mathrm{SF}_{6}$ is $7.28 \mathrm{ppq}$ currently corresponding to a radiative forcing of $0.0041 \mathrm{w} \mathrm{m}^{-2} .4,5 \mathrm{THe}$ greenhouse effect has caused widespread public concern in recent years. ${ }^{6}$ Climate deterioration caused by $\mathrm{SF}_{6}$ has gradually become one of the contradictions between power industry development and environmental protection. Hence, the power industry should gradually limit the use of $\mathrm{SF}_{6}$ and search for an

${ }^{a}$ School of Electrical Engineering, Wuhan University, BaYi Street No. 299, Wuhan 430072, Hubei Province, China. E-mail: xiaosongxs@gmail.com; Tel: +86 18986238962

${ }^{b}$ Electric Power Research Institute, China Southern Power Grid, Guangzhou 510623, China

$\dagger$ Electronic supplementary information (ESI) available. See DOI: 10.1039/c7ra09959b environmentally friendly alternative gas for $\mathrm{SF}_{6}$ in gas-insulated equipment.

$\mathrm{C}_{3} \mathrm{~F}_{7} \mathrm{CN}$ (heptafluoroisobutyronitrile) is a potential alternative gas for $\mathrm{SF}_{6}$ (see Fig. 1 for its molecular structure) with a GWP value of 2100 and Ozone Depression Potential (ODP) value of $0 .{ }^{4}$ The dielectric strength of $\mathrm{C}_{3} \mathrm{~F}_{7} \mathrm{CN}$ is 2.74 times that of $\mathrm{SF}_{6}{ }^{7}$ It should be used in combination with $\mathrm{CO}_{2}$ or other buffer gases with low liquefaction temperature due to its high liquefaction temperature (i.e., $-4.7^{\circ} \mathrm{C}$ ). In addition, the toxicity of the $\mathrm{C}_{3} \mathrm{~F}_{7} \mathrm{CN} / \mathrm{CO}_{2}$ gas mixture with $\mathrm{C}_{3} \mathrm{~F}_{7} \mathrm{CN}$ volume fraction below $10 \%$ is lower than that of pure $\mathrm{SF}_{6}$. Thus, the former is harmless to humans. ${ }^{8}$ These physical and chemical properties indicate that $\mathrm{C}_{3} \mathrm{~F}_{7} \mathrm{CN}$ is excellent in terms of environmental protection, insulation and safety, and has immense potential to replace $\mathrm{SF}_{6}$.

In the past two years, many scholars have proven that the $\mathrm{C}_{3} \mathrm{~F}_{7} \mathrm{CN} / \mathrm{CO}_{2}$ gas mixture has excellent insulation and arc extinguishing performance through numerous tests., ${ }^{3,7-10}$ For engineering applications, a gas insulated line (GIL) with a rated voltage of $420 \mathrm{kV}$ and a current transformer (CT) with a rated voltage of $245 \mathrm{kV}$ using the $\mathrm{C}_{3} \mathrm{~F}_{7} \mathrm{CN} / \mathrm{CO}_{2}$ gas mixture as insulating medium were tested in $2015{ }^{3,8}$ In addition, the investigation of the decomposition properties of a gas-insulating medium is an important component to comprehensively evaluate its performance. On the one hand, the insulation defects 


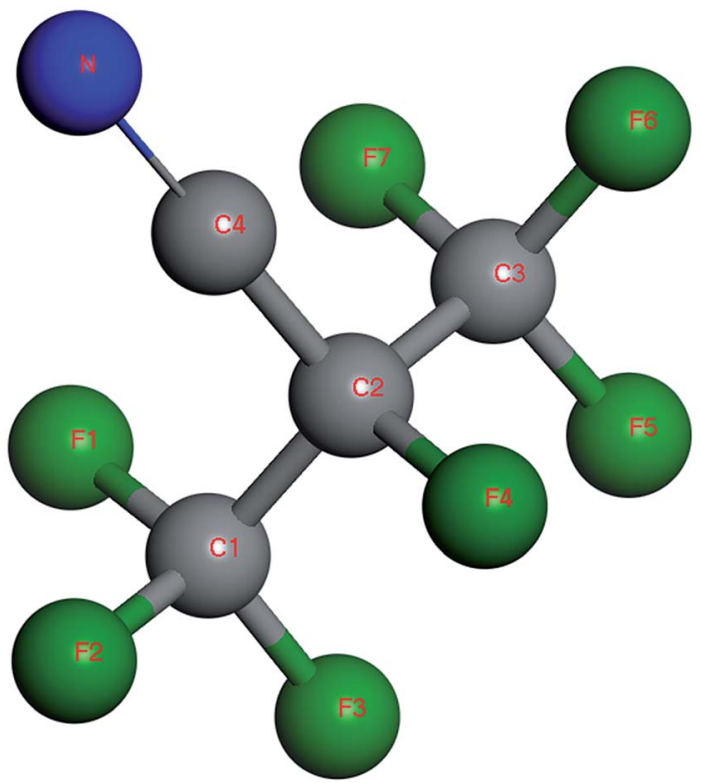

Fig. 1 Molecule structure of $\mathrm{C}_{3} \mathrm{~F}_{7} \mathrm{CN}$.

caused by aging under long-term operating conditions in electrical equipment will lead to partial discharge (PD) or flashover and is accompanied by the decomposition of the insulating medium. The local overheating fault can also lead to the decomposition of the insulating medium. On the other hand, the decomposition characteristics of the insulating medium are closely related to its self-recovery characteristics and arcextinguishing properties.

At present, researches on the decomposition characteristics of $\mathrm{C}_{3} \mathrm{~F}_{7} \mathrm{CN}$ have achieved noteworthy results. Kieffel et al. investigated the pyrolysis characteristics of the $\mathrm{C}_{3} \mathrm{~F}_{7} \mathrm{CN} / \mathrm{CO}_{2}$ gas mixture. They found the initial decomposition temperature of $\mathrm{C}_{3} \mathrm{~F}_{7} \mathrm{CN}$ was $650{ }^{\circ} \mathrm{C}$, thereby mainly producing decomposition products, such as $\mathrm{CO}, \mathrm{CF}_{3} \mathrm{CN}$, and $\mathrm{C}_{2} \mathrm{~F}_{5} \mathrm{CN}^{8}$ Andersen et al. investigated the atmospheric chemistry of $\mathrm{C}_{3} \mathrm{~F}_{7} \mathrm{CN}$ and evaluated its environmental effects based on density functional theory and infrared spectroscopy. ${ }^{11}$ Our team has explored the decomposition mechanism of $\mathrm{C}_{3} \mathrm{~F}_{7} \mathrm{CN}$ in the presence of trace water impurity through quantum chemical calculation. The ionization parameters of $\mathrm{C}_{3} \mathrm{~F}_{7} \mathrm{CN}$ and various decomposition products were analyzed from the perspective of molecular structure, thereby providing a theoretical reference for the further study of the $\mathrm{C}_{3} \mathrm{~F}_{7} \mathrm{CN}$ decomposition characteristics. ${ }^{12}$

At present, only a few studies have been conducted on the decomposition characteristics of the $\mathrm{C}_{3} \mathrm{~F}_{7} \mathrm{CN} / \mathrm{CO}_{2}$ gas mixture. Our previous studies on the decomposition mechanism of $\mathrm{C}_{3} \mathrm{~F}_{7} \mathrm{CN}$ were from the perspective of individual molecule and did not consider the decomposition process in multi-molecular and gas mixture systems. In this paper, we constructed the multi-molecular and $\mathrm{C}_{3} \mathrm{~F}_{7} \mathrm{CN} / \mathrm{CO}_{2}$ gas mixture model to study the decomposition process of $\mathrm{C}_{3} \mathrm{~F}_{7} \mathrm{CN}$ using the reactive force field molecular dynamics (ReaxFF-MD) method and density functional theory (DFT). The decomposition paths, reaction enthalpy, and products distribution of the $\mathrm{C}_{3} \mathrm{~F}_{7} \mathrm{CN}$ gas mixture at different temperatures were firstly investigated. Relevant results provide guidance for further exploration on electrical properties and practical engineering application of $\mathrm{C}_{3} \mathrm{~F}_{7} \mathrm{CN}$ gas mixture.

\section{Theoretical methods and computational details}

\subsection{ReaxFF-MD simulation details}

ReaxFF is based on bond order to describe the dissociation and formation of covalent bonds at the atomic level ${ }^{13}$ and is a beneficial tool for studying chemical reactions and predicting the performance of new materials. During the past more than ten years, ReaxFF has been used to treat a variety of elements

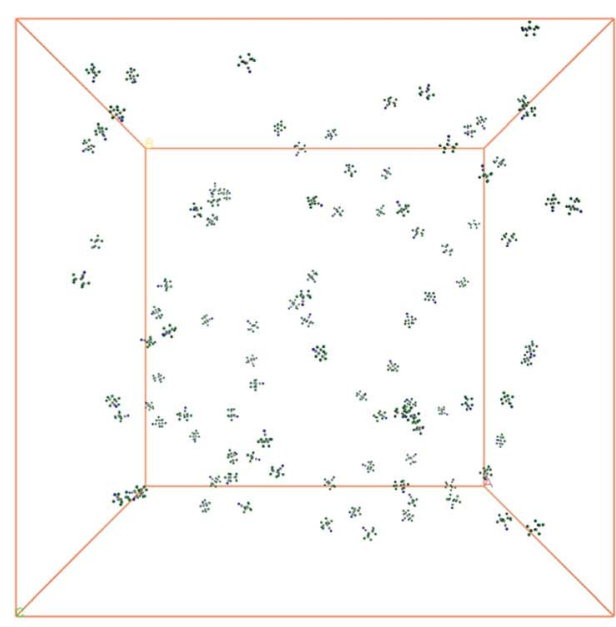

a) $\mathrm{C}_{3} \mathrm{~F}_{7} \mathrm{CN}$ system

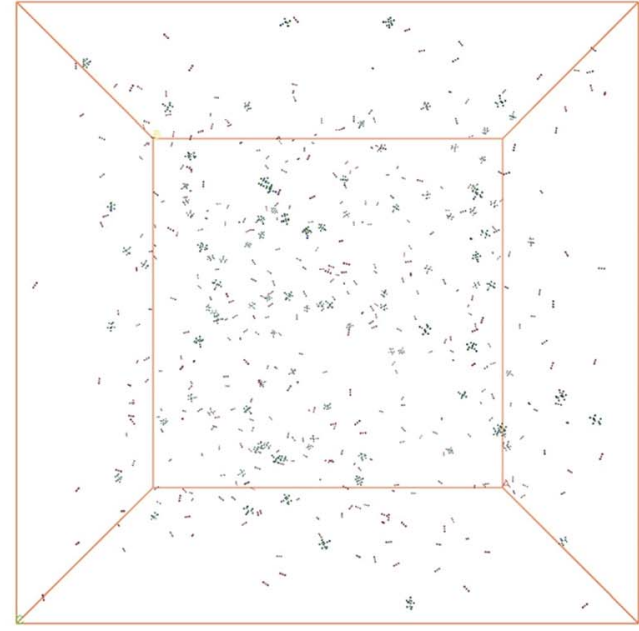

b) $\mathrm{C}_{3} \mathrm{~F}_{7} \mathrm{CN} / \mathrm{CO}_{2}$ system

Fig. 2 Configurations of the $\mathrm{C}_{3} \mathrm{~F}_{7} \mathrm{CN}$ and $\mathrm{C}_{3} \mathrm{~F}_{7} \mathrm{CN} / \mathrm{CO}_{2}$ systems. 
and multifunctional systems and is suitable for describing polyatomic systems. ${ }^{14-16}$ The energy expression of ReaxFF is presented as follows:

$$
\begin{aligned}
E_{\mathrm{system}}= & E_{\mathrm{bond}}+E_{\mathrm{over}}+E_{\mathrm{under}}+E_{\mathrm{val}}+E_{\mathrm{pen}}+E_{\mathrm{tors}}+E_{\mathrm{conj}} \\
& +E_{\mathrm{vdWaals}}+E_{\text {Coulomb }}
\end{aligned}
$$

where $E_{\text {bond }}$ corresponds to bond energy; $E_{\text {over }}$ and $E_{\text {under }}$ denote the over and under coordinated atoms, respectively, in the energy contribution; $E_{\mathrm{val}}, E_{\mathrm{pen}}, E_{\mathrm{tors}}, E_{\mathrm{conj}}, E_{\mathrm{vdWaals}}$, and $E_{\mathrm{Coulomb}}$ represent the valence angle term, penalty energy, torsion energy, conjugation effects to energy, nonbonded van der Waals interaction, and Coulomb interaction, respectively.

Two periodic cubic boxes were built to explore the decomposition of $\mathrm{C}_{3} \mathrm{~F}_{7} \mathrm{CN}$ and the $\mathrm{C}_{3} \mathrm{~F}_{7} \mathrm{CN} / \mathrm{CO}_{2}$ gas mixture (see Fig. 2). The $\mathrm{C}_{3} \mathrm{~F}_{7} \mathrm{CN}$ system contains $100 \mathrm{C}_{3} \mathrm{~F}_{7} \mathrm{CN}$ molecules with a density of $0.00811 \mathrm{~g} \mathrm{~cm}^{-3}$. The length of the box is $159 \AA$. At present, many scholars have tested the insulation characteristics of $\mathrm{C}_{3} \mathrm{~F}_{7} \mathrm{CN} / \mathrm{CO}_{2}$ mixture and found that mixtures with $20 \%$ $\mathrm{C}_{3} \mathrm{~F}_{7} \mathrm{CN}$ displayed dielectric strengths comparable to $\mathrm{SF}_{6} \cdot{ }^{4,7}$ In order to reveal the decomposition properties of mixtures in this scale, we built the $\mathrm{C}_{3} \mathrm{~F}_{7} \mathrm{CN} / \mathrm{CO}_{2}$ system which contains 100 $\mathrm{C}_{3} \mathrm{~F}_{7} \mathrm{CN}$ molecules and $400 \mathrm{CO}_{2}$ molecules with a density of $0.00351 \mathrm{~g} \mathrm{~cm}^{-3}$. The length of the box is $260 \AA$. The initial density corresponds to the actual density of $\mathrm{C}_{3} \mathrm{~F}_{7} \mathrm{CN}$ under $25^{\circ} \mathrm{C}$ and 0.1 Mpa. The system was minimized with the NVE ensemble for $5 \mathrm{ps}$ at $5 \mathrm{~K}$ and equilibrated with the NVT ensemble thereafter for $10 \mathrm{ps}$ at $1000 \mathrm{~K}$ using a time step of 0.1 fs. ${ }^{16}$ The NVT simulations were then conducted at different temperatures for 1000 ps to explore the decomposition process of $\mathrm{C}_{3} \mathrm{~F}_{7} \mathrm{CN}$ and $\mathrm{C}_{3} \mathrm{~F}_{7} \mathrm{CN} / \mathrm{CO}_{2}$ gas mixture. The temperature was controlled by the method of a Berendsen thermostat with a 0.1 ps damping constant. ${ }^{17}$ All the ReaxFF-MD simulations in this paper were performed based on the ReaxFF module of ADF (Amsterdam Density Functional). ${ }^{18}$

\subsection{DFT calculation details}

The first principle of calculations based on the density functional theory (DFT) was performed to obtain the precise dissociation energy of $\mathrm{C}_{3} \mathrm{~F}_{7} \mathrm{CN}$ at different temperatures. This theory is widely used in the study of chemical reaction mechanisms, and can describe any given chemical system with high accuracy. ${ }^{19-21}$

The spin unrestricted DFT calculation in the current study was performed based on the Dmol 3 module of the Materials studio 8.0. The meta-generalized approximation (mGGA) method treated by M06L functions is used to describe the exchange-correlation energy. This local density functional does well for predicting geometries and vibrational frequencies and gives great performance for a combination of main-group thermochemistry and thermochemical kinetics. ${ }^{22,23}$ The double numerical atomic orbital augmented by d-polarization (DNP) is used as the basis set. Geometry optimizations were performed with the following convergence parameters: (1) energy convergence tolerance of $1.0 \times 10^{-5} \mathrm{Ha}$, (2) maximum force of $0.002 \mathrm{Ha} \AA^{-1}$, and (3) maximum displacement of 0.005 $\AA$ A. It should be pointed that spin contamination (unrestricted
DFT is much less affected by it than unrestricted Hartree-Fock theory $^{24}$ ) and wave function unstability may occur in spin unrestricted calculation. The self-consistent-field (SCF) solution stability is checked to ensure the accuracy of calculation results.

The enthalpy correction is presented as follows to obtain the precise energy of the system at a given temperature: ${ }^{25}$

$$
\Delta E=\sum\left(E_{\text {product }}+\Delta E_{\text {product }}\right)-\sum\left(E_{\text {reactant }}+\Delta E_{\text {reactant }}\right),
$$

where $E_{\text {product }}$ and $E_{\text {reactant }}$ correspond to the energy of the product and reactant, respectively, at $0 \mathrm{~K}$ and $\Delta E_{\text {product }}$ and $\Delta E_{\text {reactant }}$ correspond to the correcting values of the enthalpy of product and reactant, respectively, at a given temperature.

\section{Results and discussion}

\subsection{Decomposition of the pure $\mathrm{C}_{3} \mathrm{~F}_{7} \mathrm{CN}$}

3.1.1 Decomposition process and main reaction paths. The three main types of discharges in electrical equipment are the corona (partial discharge), arc, and spark discharges, wherein the corona and arc discharges are the most common. ${ }^{26}$ The maximum temperature in the central region of the corona discharge is in the range of $700-1200 \mathrm{~K}$ and the highest temperature in the arc discharge region can reach $12000 \mathrm{~K}^{26-28}$ The current study analyzed the decomposition mechanism of $\mathrm{C}_{3} \mathrm{~F}_{7} \mathrm{CN}$ and its gas mixture at different temperatures to clarify the particle composition and product change. It should be noted that the time scale of ReaxFF MD simulation is normally limited to several dozens of nanoseconds due to the computational cost. ${ }^{28,29}$ Hence, we enhance the temperatures to accelerate the simulation process to allow reactions can be observed.

First, the multi-molecular ReaxFF molecular dynamic simulations of $\mathrm{C}_{3} \mathrm{~F}_{7} \mathrm{CN}$ were performed and demonstrated that the $\mathrm{C}_{3} \mathrm{~F}_{7} \mathrm{CN}$ molecule began to decompose at $1900 \mathrm{~K}$. Fig. 3 shows the time evolution of the major species of the $\mathrm{C}_{3} \mathrm{~F}_{7} \mathrm{CN}$ decomposition at $1900 \mathrm{~K}$. Table 1 shows the generation time of the major species and corresponding decomposition pathways. At $1900 \mathrm{~K}$, the $\mathrm{C}_{3} \mathrm{~F}_{7} \mathrm{CN}$ decomposition mainly produces free radicals, such as $\mathrm{CF}_{3}, \mathrm{C}_{3} \mathrm{~F}_{7}, \mathrm{CN}, \mathrm{CNF}, \mathrm{CF}_{2}, \mathrm{CF}, \mathrm{CF}_{3} \mathrm{CFCN}\left(\mathrm{C}_{3} \mathrm{NF}_{4}\right)$, and $\mathrm{F}$. It is important to note that some free radicals, such as

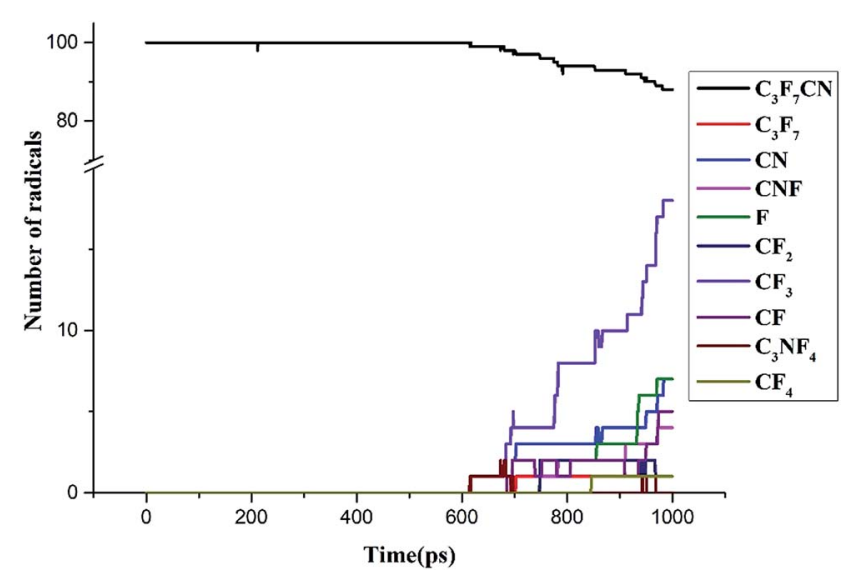

Fig. 3 Time evolution of the major species at $1900 \mathrm{~K}$. 
Table 1 Generation time of the major species and corresponding decomposition pathways

\begin{tabular}{|c|c|c|c|c|}
\hline Major species & Generation time (ps) & Reaction & & $\Delta E^{a}\left(\mathrm{kcal} \mathrm{mol}^{-1}\right)$ \\
\hline $\mathrm{C}_{3} \mathrm{NF}_{4}, \mathrm{CF}_{3}$ & 615 & $\mathrm{~A}$ & $\mathrm{C}_{3} \mathrm{~F}_{7} \mathrm{CN} \rightarrow \mathrm{CF}_{3}+\mathrm{CF}_{3} \mathrm{CFCN}$ & 72.67 \\
\hline $\mathrm{C}_{3} \mathrm{~F}_{7}$ & 702.5 & $\mathrm{~B}$ & $\mathrm{C}_{3} \mathrm{~F}_{7} \mathrm{CN} \rightarrow \mathrm{C}_{3} \mathrm{~F}_{7}+\mathrm{CN}$ & 101.33 \\
\hline $\mathrm{CN}, \mathrm{CF}$ & 685.625 & $\mathrm{D}$ & $\mathrm{CF}_{3} \mathrm{CFCN} \rightarrow \mathrm{CF}_{3}+\mathrm{CF}+\mathrm{CN}$ & 174.66 \\
\hline $\mathrm{CF}_{2}, \mathrm{~F}$ & 748.125 & $\mathrm{E}$ & $\mathrm{CF}_{3} \rightarrow \mathrm{CF}_{2}+\mathrm{F}$ & 79.04 \\
\hline $\mathrm{CNF}$ & 748.125 & $\mathrm{~F}$ & $\mathrm{CN}+\mathrm{F} \rightarrow \mathrm{CNF}$ & -118.48 \\
\hline
\end{tabular}

${ }^{a} T=1900 \mathrm{~K}$, at mGGA-M06L level with ZPE and enthalpy corrections.

$\mathrm{CN}$, are harmful free radicals and could produce toxic molecules. The content and toxicity of the decomposition products of $\mathrm{C}_{3} \mathrm{~F}_{7} \mathrm{CN}$ need further test study before engineering application.

$\mathrm{C}_{3} \mathrm{~F}_{7} \mathrm{CN}$ began to decompose at $615 \mathrm{ps}$, thereby producing $\mathrm{CF}_{3} \mathrm{CFCN}$ and $\mathrm{CF}_{3}$. This reaction path is required to absorb $72.67 \mathrm{kcal} \mathrm{mol}^{-1}$. Another decomposing path began at $702.5 \mathrm{ps,}$ thereby producing $\mathrm{C}_{3} \mathrm{~F}_{7}$ and $\mathrm{CN}$ and needs to absorb $101.33 \mathrm{kcal} \mathrm{mol}^{-1}$. In addition, the decomposition of $\mathrm{CF}_{3} \mathrm{CFCN}$ is at $685.625 \mathrm{ps}$, thereby generating $\mathrm{CF}_{3}, \mathrm{CF}$, and $\mathrm{CN} . \mathrm{CF}_{3}$ can further decompose to $\mathrm{CF}_{2}$ and $\mathrm{F}$ by absorbing $79.04 \mathrm{kcal} \mathrm{mol}^{-1}$, $\mathrm{CF}$ can further decompose to $\mathrm{C}$ and $\mathrm{F}$ by absorbing $121.23 \mathrm{kcal} \mathrm{mol}{ }^{-1} \cdot \mathrm{CF}_{4}$ is one of the stable decomposition products, which is formed by $\mathrm{CF}_{3}$ and $\mathrm{F}$ and releases $-107.64 \mathrm{kcal} \mathrm{mol}^{-1}$. In addition, the DFT calculation results show that the energy required for path $\mathrm{A}$ is lower than that for path $\mathrm{B}$, which means that path $\mathrm{A}$ is more likely to occur than path $\mathrm{B}$. And the ReaxFF-MD results show that the number of generated $\mathrm{CF}_{3}$ increases rapidly during 700-1000 ps, which indicates the results of ReaxFF are consistent with DFT calculations and the performance of ReaxFF is reliable.

3.1.2 Effect of temperature on the decomposition process. To further analyze the influence of temperature on the

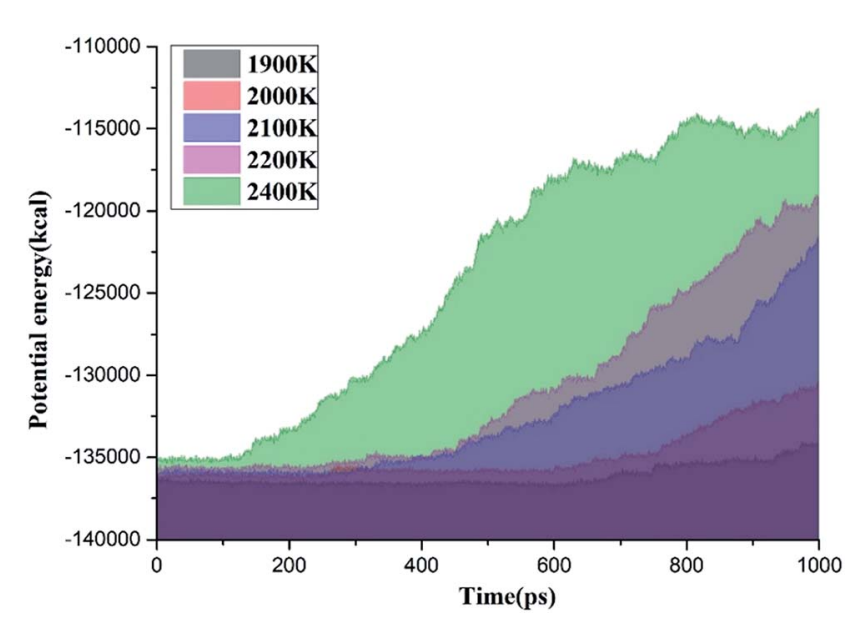

Fig. 4 Time evolution of the potential energy between $1900 \mathrm{~K}$ and $2400 \mathrm{~K}\left(\mathrm{C}_{3} \mathrm{~F}_{7} \mathrm{CN}\right.$ system). decomposition process of $\mathrm{C}_{3} \mathrm{~F}_{7} \mathrm{CN}$, the molecular dynamic simulation of the $\mathrm{C}_{3} \mathrm{~F}_{7} \mathrm{CN}$ system was performed at five temperature zones, that is, $1900 \mathrm{~K}, 2000 \mathrm{~K}, 2100 \mathrm{~K}, 2200 \mathrm{~K}$, and $2400 \mathrm{~K}$, for a total simulation time of $1000 \mathrm{ps}$.

Fig. 4 shows the time evolution of the potential energy between $1900 \mathrm{~K}$ and $2400 \mathrm{~K}$. The potential energy of the system increases during the reaction process at different temperatures,

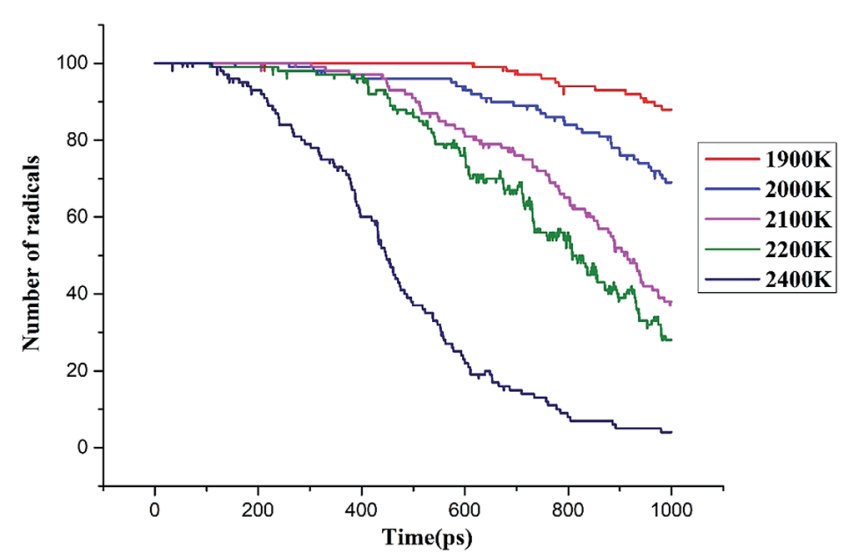

Fig. 5 Time evolution of the $\mathrm{C}_{3} \mathrm{~F}_{7} \mathrm{CN}$ molecules decomposition when temperature is increased from 1900 to $2400 \mathrm{~K}$ ( $\mathrm{C}_{3} \mathrm{~F}_{7} \mathrm{CN}$ system).

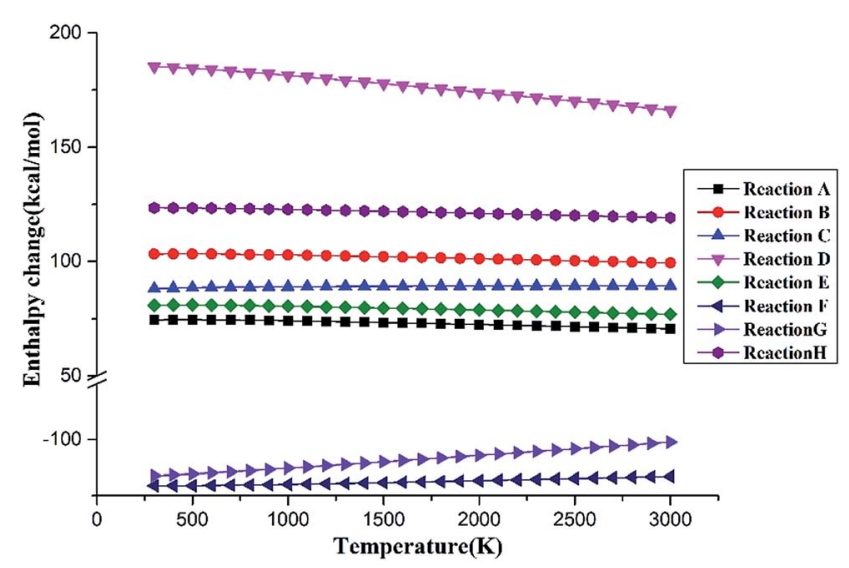

Fig. 6 Enthalpy change of the reaction pathways from $300 \mathrm{~K}$ to $3000 \mathrm{~K}$. 


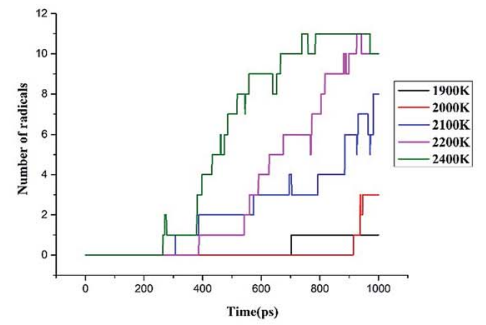

a) $\mathrm{C}_{3} \mathrm{~F}_{7}$

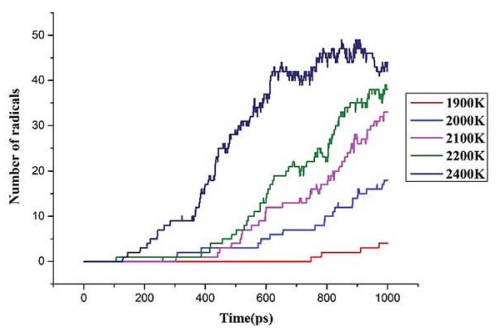

c) $\mathrm{CNF}$

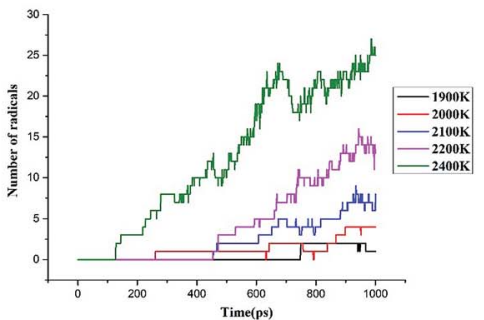

e) $\mathrm{CF}_{2}$

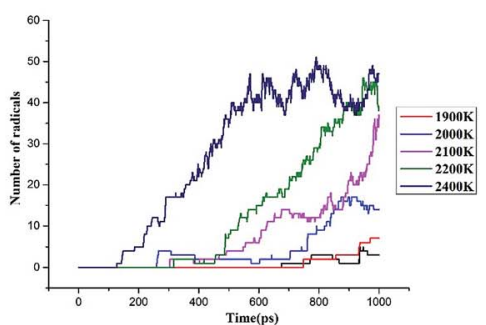

g) F

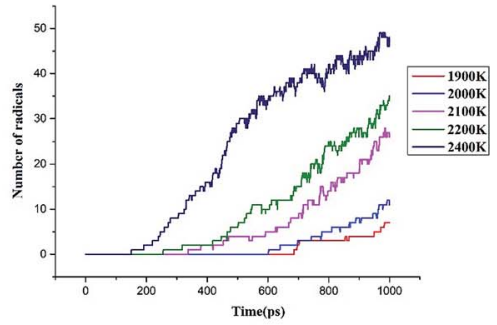

b) $\mathrm{CN}$

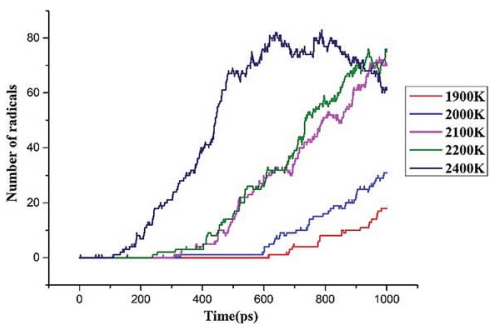

d) $\mathrm{CF}_{3}$

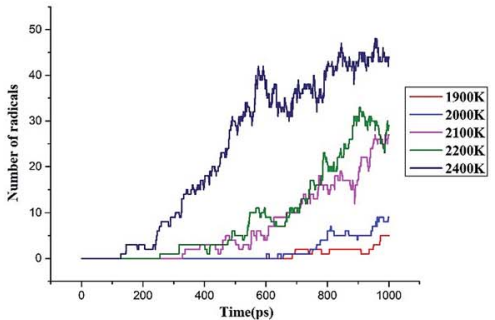

f) $\mathrm{CF}$

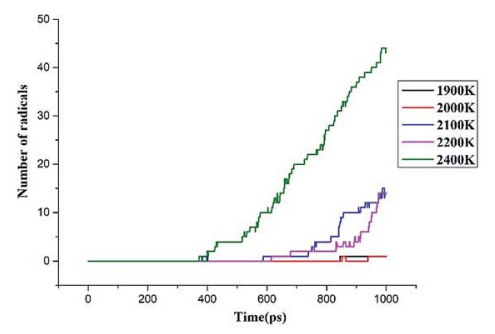

h) $\mathrm{CF}_{4}$

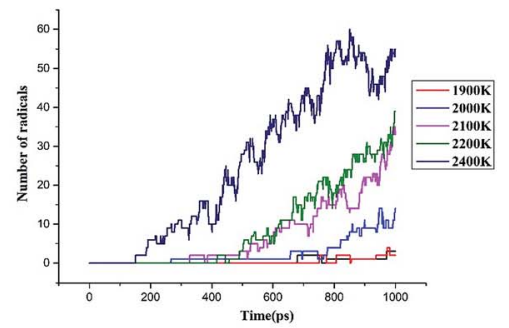

i) $\mathrm{C}$

Fig. 7 Time evolution of the major species between $1900 \mathrm{~K}$ and $2400 \mathrm{~K}\left(\mathrm{C}_{3} \mathrm{~F}_{7} \mathrm{CN}\right.$ system).

thereby indicating that the entire decomposition process of $\mathrm{C}_{3} \mathrm{~F}_{7} \mathrm{CN}$ needs to absorb energy. The growth rate of the potential energy is evidently accelerated with the increase of temperature, indicating that the increase of the ambient temperature will lead to the accelerated decomposition of $\mathrm{C}_{3} \mathrm{~F}_{7} \mathrm{CN}$. When the ambient temperature reaches $2400 \mathrm{~K}$, the growth rate of the 


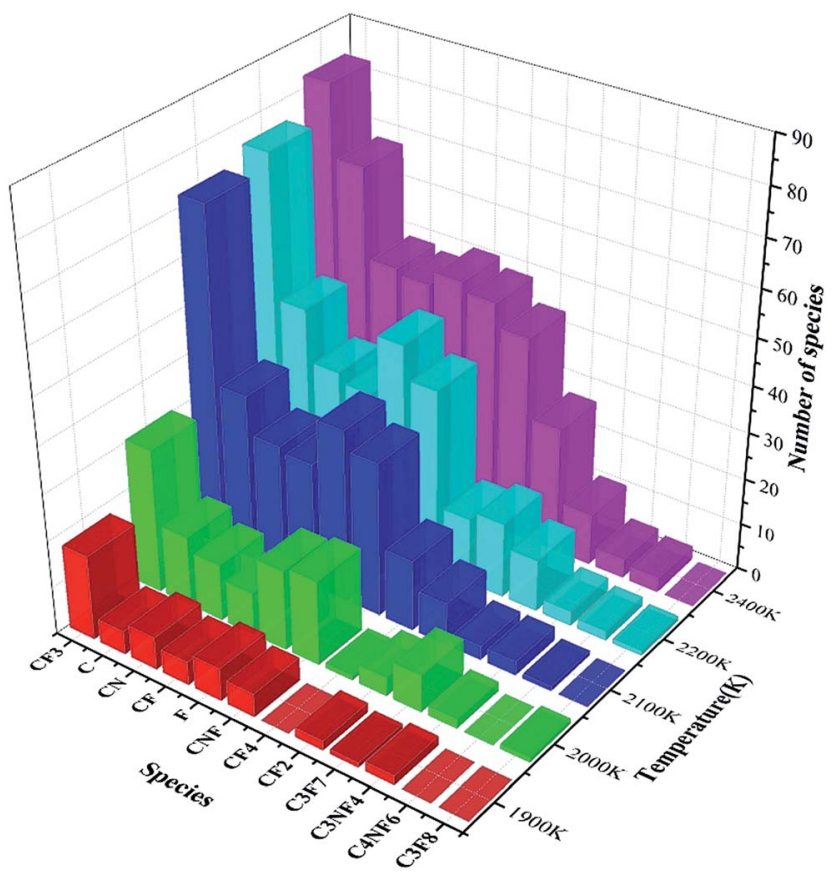

Fig. 8 Number of produced species in $\mathrm{C}_{3} \mathrm{~F}_{7} \mathrm{CN}$ at different temperatures.

potential energy in the time range of $125 \mathrm{ps}$ to $600 \mathrm{ps}$ is significantly higher than that of $600-1000$ ps. This result indicates that the reactions in the system before 600 ps are mainly absorbed energy. Moreover, exothermic reactions may occur in the system after $600 \mathrm{ps}$, thereby leading to the considerably gradual growth of the overall potential energy.

Fig. 5 illustrates the time evolution of the $\mathrm{C}_{3} \mathrm{~F}_{7} \mathrm{CN}$ molecules between $1900 \mathrm{~K}$ and $2400 \mathrm{~K}$. The decomposition rate and quantity of the $\mathrm{C}_{3} \mathrm{~F}_{7} \mathrm{CN}$ molecules are evidently accelerated with the increase of temperature. For example, only $8 \mathrm{C}_{3} \mathrm{~F}_{7} \mathrm{CN}$ molecules decomposed at $1900 \mathrm{~K}$, whereas $96 \mathrm{C}_{3} \mathrm{~F}_{7} \mathrm{CN}$ molecules decomposed at $2400 \mathrm{~K}$ at the end of the molecular dynamic simulation.

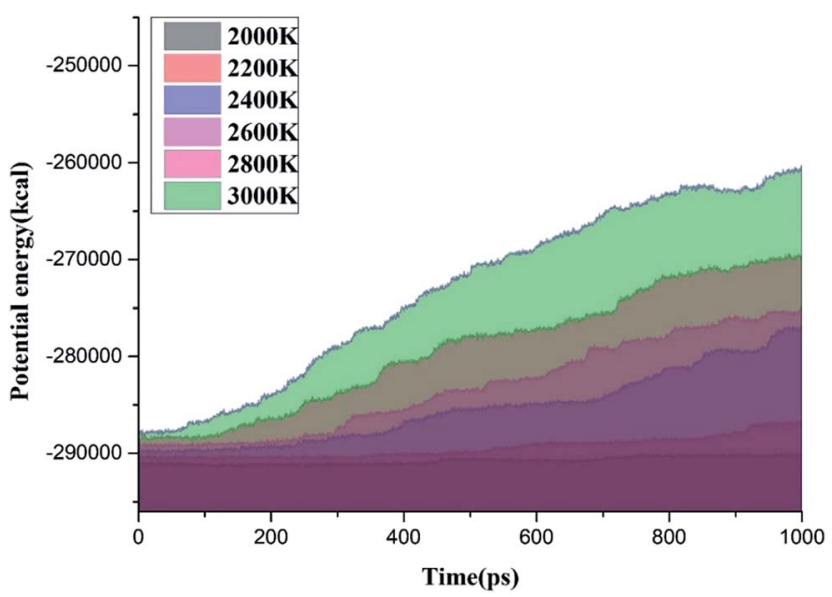

Fig. 9 Time evolution of the potential energy between $2000 \mathrm{~K}$ and $3000 \mathrm{~K}\left(\mathrm{C}_{3} \mathrm{~F}_{7} \mathrm{CN} / \mathrm{CO}_{2}\right.$ system).
To further analyze the effect of temperature on the decomposition of $\mathrm{C}_{3} \mathrm{~F}_{7} \mathrm{CN}$, the enthalpy of the main reaction paths in the temperature range of $300-3000 \mathrm{~K}$ is calculated based on DFT (see Fig. 6). As the temperature increases, the reaction enthalpy of paths $\mathrm{A}, \mathrm{B}, \mathrm{D}$, and $\mathrm{E}$ decreases, that is, the temperature increase is favorable for the reaction progress. The enthalpy change of path $\mathrm{D}$ is the most evident, thereby indicating that the increase of temperature has a significant effect on the decomposition of $\mathrm{CF}_{3} \mathrm{CFCN}$. The reaction enthalpy change of paths $\mathrm{C}$ and $\mathrm{H}$ is not significantly with increasing temperature. Paths $\mathrm{F}$ and $\mathrm{G}$ are exothermic reaction processes and the energy released decreases as the temperature increases.

3.1.3 Intermediates and main products. Fig. 7 illustrates the time evolution of the major species of $\mathrm{C}_{3} \mathrm{~F}_{7} \mathrm{CN}$ decomposition over the temperature range from $1900 \mathrm{~K}$ to $2400 \mathrm{~K}$. Fig. 8 shows the maximum number of produced species. The statistical results in Fig. 7 shows that the amount of $\mathrm{C}_{3} \mathrm{~F}_{7}, \mathrm{CN}, \mathrm{CNF}$, $\mathrm{CF}_{3}, \mathrm{CF}_{2}, \mathrm{CF}, \mathrm{CF}_{3} \mathrm{CFCN}\left(\mathrm{C}_{3} \mathrm{NF}_{4}\right), \mathrm{F}$, and other free radicals and $\mathrm{CF}_{4}$ produced by the decomposition of $\mathrm{C}_{3} \mathrm{~F}_{7} \mathrm{CN}$ increased with the increase of temperature.

The statistical results in Fig. 8 show that the content of $\mathrm{CF}_{3}$ at each temperature is the highest among all the products, while the contents of $\mathrm{CF}_{2}, \mathrm{CN}, \mathrm{CNF}$, and $\mathrm{F}$ are similar. The contents of $\mathrm{C}_{3} \mathrm{~F}_{7}$, $\mathrm{C}_{3} \mathrm{NF}_{4}$, and $\mathrm{C}_{4} \mathrm{NF}_{6}$ are lower compared with those of other products. $\mathrm{C}_{4} \mathrm{NF}_{6}$ is generated by the dissociation of the $\mathrm{F}$ atom in the $\mathrm{C}_{3} \mathrm{~F}_{7} \mathrm{CN}$ molecule from the central $\mathrm{C}$ atom $(\mathrm{C} 2$ atom as shown in Fig. 1), thereby requiring the absorption of $89.17 \mathrm{kcal} \mathrm{mol}^{-1}$. In addition, a few small stable molecules, such as $\mathrm{CF}_{4}$ and $\mathrm{C}_{3} \mathrm{~F}_{8}$, are found during the simulation. The generation rate of $\mathrm{CF}_{4}$ in the time range of $600-1000 \mathrm{ps}$ at $2400 \mathrm{~K}$ increased and the amount of $\mathrm{CF}_{3}$ and $\mathrm{F}$ during the time range reduced (as shown in Fig. 7). Given that the generation path of $\mathrm{CF}_{4}$ (path $\mathrm{G}$ in Table 1) is exothermic, the gradual growth of the overall potential energy of the system is actually due to the large amount of $\mathrm{CF}_{4}$ produced.

\subsection{Decomposition of the $\mathrm{C}_{3} \mathrm{~F}_{7} \mathrm{CN} / \mathrm{CO}_{2}$ mixture}

3.2.1 Effect of temperature on the decomposition process. In order to obtain the decomposition properties of the insulating medium in a practical application condition, the

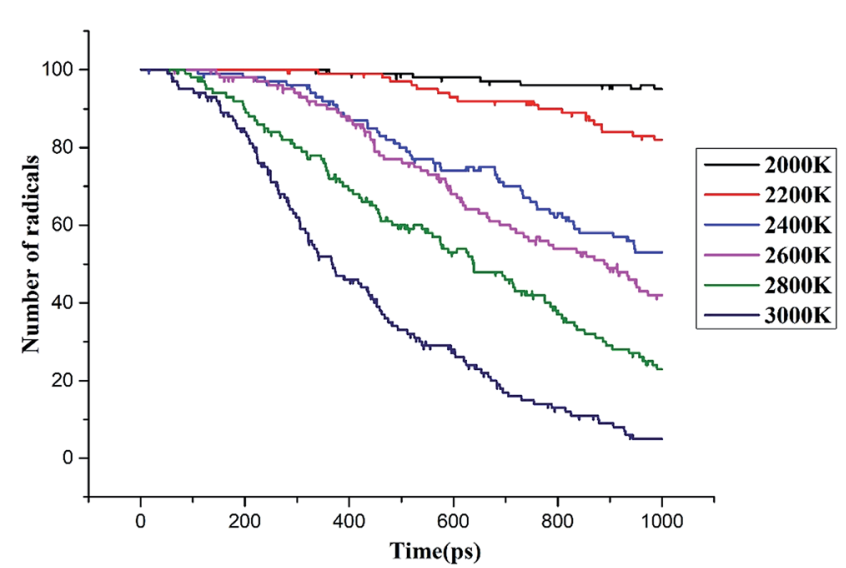

Fig. 10 Time evolution of the $\mathrm{C}_{3} \mathrm{~F}_{7} \mathrm{CN}$ molecules decomposition when temperature is increased from 2000 to $3000 \mathrm{~K}\left(\mathrm{C}_{3} \mathrm{~F}_{7} \mathrm{CN} / \mathrm{CO}_{2}\right.$ system). 


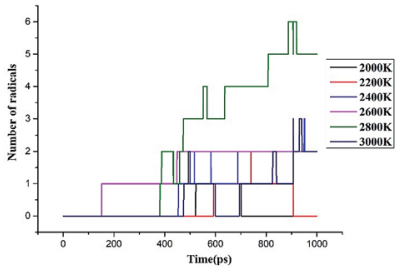

a) $\mathrm{C}_{3} \mathrm{~F}_{7}$

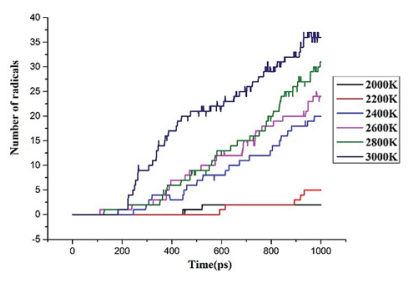

c) $\mathrm{CNF}$

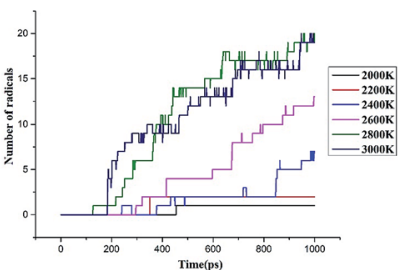

e) $\mathrm{CF}_{2}$

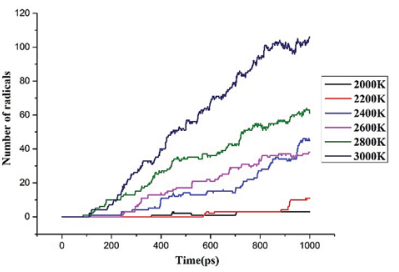

g) $F$

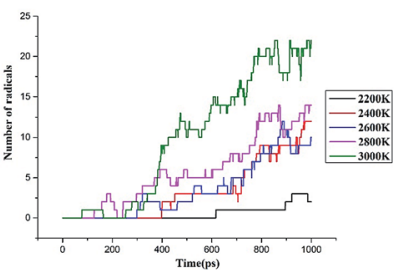

i) $\mathrm{C}$

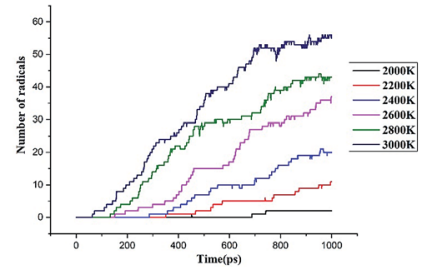

b) $\mathrm{CN}$

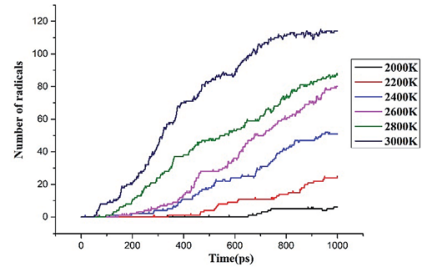

d) $\mathrm{CF}_{3}$

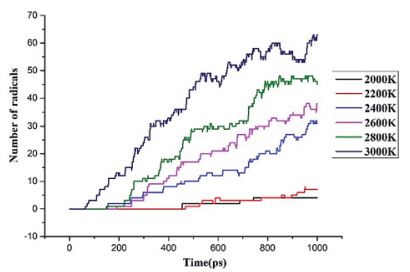

f) $\mathrm{CF}$

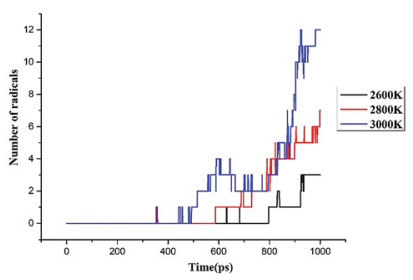

h) $\mathrm{CF}_{4}$

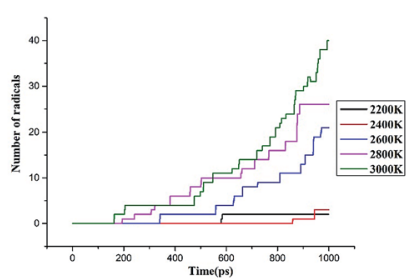

j) $\mathrm{CO}$

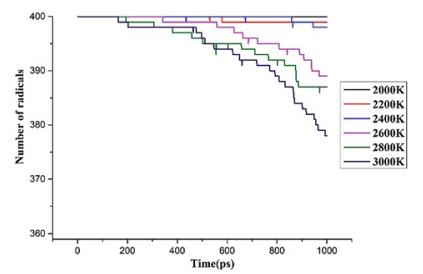

k) $\mathrm{CO}_{2}$

Fig. 11 Time evolution of the major species between $2000 \mathrm{~K}$ and $3000 \mathrm{~K}\left(\mathrm{C}_{3} \mathrm{~F}_{7} \mathrm{CN} / \mathrm{CO}_{2}\right.$ system).

decomposition characteristics of $\mathrm{C}_{3} \mathrm{~F}_{7} \mathrm{CN} / \mathrm{CO}_{2}$ gas mixture over the temperature range from $2000 \mathrm{~K}$ to $3000 \mathrm{~K}$ were discussed. Fig. 9 shows the time evolution of the potential energy of the

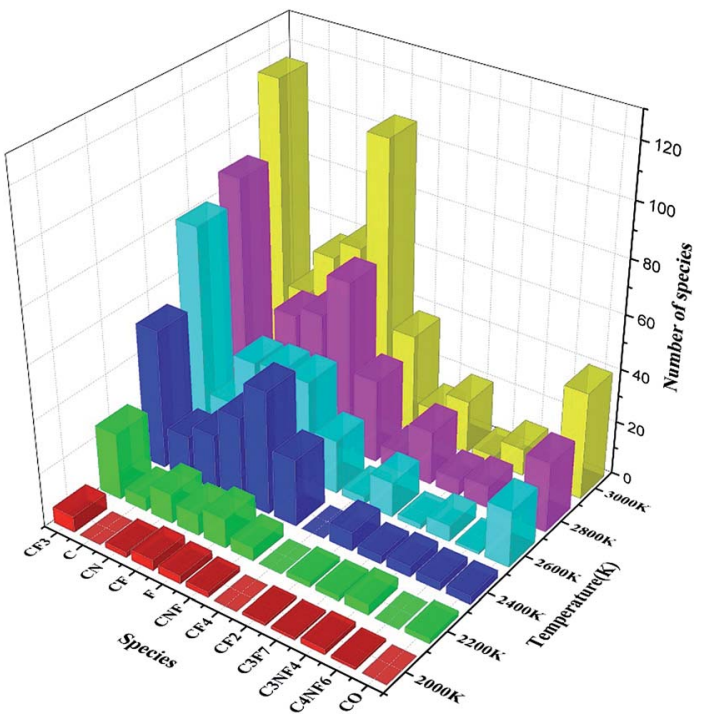

Fig. 12 Number of produced species in $\mathrm{C}_{3} \mathrm{~F}_{7} \mathrm{CN} / \mathrm{CO}_{2}$ at different temperatures.

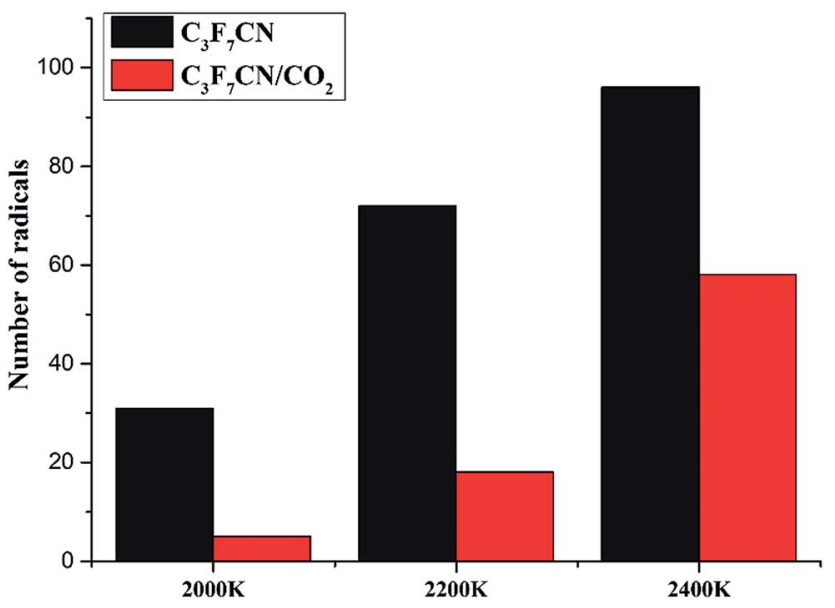

Fig. 13 Final decomposition amount of $\mathrm{C}_{3} \mathrm{~F}_{7} \mathrm{CN}$ at different temperatures.

$\mathrm{C}_{3} \mathrm{~F}_{7} \mathrm{CN} / \mathrm{CO}_{2}$ gas mixture system. Fig. 10 provides the decomposition amount of $\mathrm{C}_{3} \mathrm{~F}_{7} \mathrm{CN}$.

The potential energy of the system shows an increasing trend in the range of 2200-3000 K. When the ambient temperature is above $2400 \mathrm{~K}$, the potential energy of the system increases. When the ambient temperature is $2000 \mathrm{~K}$, the potential energy of the system does not change substantially, thereby exhibiting a relationship with the decomposition degree when $\mathrm{C}_{3} \mathrm{~F}_{7} \mathrm{CN}$ is low. The decomposition rate of $\mathrm{C}_{3} \mathrm{~F}_{7} \mathrm{CN}$ is accelerated with the increase of temperature, thereby showing consistency with the conclusion of the pure $\mathrm{C}_{3} \mathrm{~F}_{7} \mathrm{CN}$ system.

3.2.2 Intermediates and main products. Fig. 11 describes the time evolution of the major decomposition species of $\mathrm{C}_{3} \mathrm{~F}_{7} \mathrm{CN}$ over the temperature range from $2000 \mathrm{~K}$ to $3000 \mathrm{~K}$. Fig. 12 presents the maximum number of produced species. 
Table 2 Final amount of the decomposition products at different temperatures

\begin{tabular}{|c|c|c|c|c|c|c|}
\hline Major species & \multicolumn{6}{|c|}{ Temperature } \\
\hline $\mathrm{C}_{3} \mathrm{~F}_{7}$ & 8 & 1 & 11 & 2 & 11 & 3 \\
\hline $\mathrm{CF}_{3}$ & 31 & 6 & 76 & 25 & 83 & 52 \\
\hline $\mathrm{CN}$ & 12 & 2 & 35 & 11 & 49 & 21 \\
\hline $\mathrm{CNF}$ & 18 & 2 & 39 & 5 & 49 & 25 \\
\hline $\mathrm{F}$ & 17 & 3 & 46 & 11 & 51 & 46 \\
\hline $\mathrm{C}_{3} \mathrm{NF}_{4}$ & 2 & 2 & 3 & 4 & 4 & 4 \\
\hline $\mathrm{C}_{4} \mathrm{NF}_{6}$ & 0 & 1 & 2 & 0 & 3 & 3 \\
\hline $\mathrm{CF}_{4}$ & 1 & 0 & 14 & 0 & 44 & 0 \\
\hline
\end{tabular}

Similar to the pure $\mathrm{C}_{3} \mathrm{~F}_{7} \mathrm{CN}$ system, the content of the major decomposition products shows an increasing trend with the increase of temperature. The content of $\mathrm{CF}_{3}$ in the products is the highest at each temperature. When the temperature is below $2800 \mathrm{~K}$, the yields of $\mathrm{CN}$, CNF, CF, and $\mathrm{F}$ are similar. When the temperature is above $2800 \mathrm{~K}$, the content of $\mathrm{F}$ in the system increases. A new decomposition of products, namely, $\mathrm{CO}$, is produced due to the addition of $\mathrm{CO}_{2}$. The decomposition of $\mathrm{CO}_{2}$ accelerated at temperatures over $2600 \mathrm{~K}$ and 40 molecules of $\mathrm{CO}$ are produced at $3000 \mathrm{~K}$. In the $\mathrm{C}_{3} \mathrm{~F}_{7} \mathrm{CN} / \mathrm{CO}_{2}$ system, the yield of $\mathrm{CF}_{4}$ reduces. Only $12 \mathrm{CF}_{4}$ molecules were produced at $3000 \mathrm{~K}$ at the end of the simulation, which is lower than that of the pure $\mathrm{C}_{3} \mathrm{~F}_{7} \mathrm{CN}$ system. In addition, the generation rate of $\mathrm{CF}_{3}$ and $\mathrm{F}$ after $800 \mathrm{ps}$ at $3000 \mathrm{~K}$ slowed down, which is related to the formation of $\mathrm{CF}_{4}$.

3.2.3 Effect of $\mathrm{CO}_{2}$ on the decomposition process. Fig. 13 shows the final decomposition amount of $\mathrm{C}_{3} \mathrm{~F}_{7} \mathrm{CN}$ in $\mathrm{C}_{3} \mathrm{~F}_{7} \mathrm{CN}$ and $\mathrm{C}_{3} \mathrm{~F}_{7} \mathrm{CN} / \mathrm{CO}_{2}$ system at the same temperature. The decomposition amount of $\mathrm{C}_{3} \mathrm{~F}_{7} \mathrm{CN}$ in the $\mathrm{C}_{3} \mathrm{~F}_{7} \mathrm{CN} / \mathrm{CO}_{2}$ gas mixture system is lower than that in the pure $\mathrm{C}_{3} \mathrm{~F}_{7} \mathrm{CN}$ system at the same temperature. For example, the decomposition amount in the pure $\mathrm{C}_{3} \mathrm{~F}_{7} \mathrm{CN}$ system is 96 at $2400 \mathrm{~K}$, whereas that of the $\mathrm{C}_{3} \mathrm{~F}_{7} \mathrm{CN} /$ $\mathrm{CO}_{2}$ gas mixture system is 58 . The addition of the buffer gas $\mathrm{CO}_{2}$ can effectively inhibit the decomposition of $\mathrm{C}_{3} \mathrm{~F}_{7} \mathrm{CN}$.

Table 2 shows that the final amount of the decomposition products in the $\mathrm{C}_{3} \mathrm{~F}_{7} \mathrm{CN} / \mathrm{CO}_{2}$ gas mixture system is lower than that in the pure $\mathrm{C}_{3} \mathrm{~F}_{7} \mathrm{CN}$ system at the same temperature. Moreover, the addition of $\mathrm{CO}_{2}$ inhibits the formation of $\mathrm{CF}_{4}$ and $\mathrm{C}$, thereby making it difficult for the system to precipitate carbon and produce products with relatively poor insulation properties. This result is beneficial to protect the insulation properties of the system.

Therefore, the $\mathrm{C}_{3} \mathrm{~F}_{7} \mathrm{CN} / \mathrm{CO}_{2}$ gas mixture is relatively suitable for using as a gas-insulated medium relative to pure $\mathrm{C}_{3} \mathrm{~F}_{7} \mathrm{CN}$. The mechanism of the action of $\mathrm{CO}_{2}$ over $\mathrm{C}_{3} \mathrm{~F}_{7} \mathrm{CN}$ to avoid its decomposition process in function of temperature needs further study.

\section{Conclusion}

This study analyzed the decomposition characteristics of $\mathrm{C}_{3} \mathrm{~F}_{7} \mathrm{CN}$ and its gas mixture based on ReaxFF-MD method and density functional theory. The main decomposition pathways, reaction enthalpy, and the composition of the main decomposition products of $\mathrm{C}_{3} \mathrm{~F}_{7} \mathrm{CN}$ at different temperatures were revealed. The decomposition characteristics of $\mathrm{C}_{3} \mathrm{~F}_{7} \mathrm{CN}$ and $\mathrm{C}_{3} \mathrm{~F}_{7} \mathrm{CN} / \mathrm{CO}_{2}$ gas mixture were compared and analyzed.

The decomposition of $\mathrm{C}_{3} \mathrm{~F}_{7} \mathrm{CN}$ mainly produces $\mathrm{CF}_{3}, \mathrm{C}_{3} \mathrm{~F}_{7}$, $\mathrm{CN}, \mathrm{CNF}, \mathrm{CF}_{2}, \mathrm{CF}, \mathrm{F}$, and other free radicals and a few molecular products, such as $\mathrm{CF}_{4}$ and $\mathrm{C}_{3} \mathrm{~F}_{8}$. The decomposition rate of $\mathrm{C}_{3} \mathrm{~F}_{7} \mathrm{CN}$ and generation rate of the products increase with the increase of ambient temperature. The $\mathrm{C}_{3} \mathrm{~F}_{7} \mathrm{CN} / \mathrm{CO}_{2}$ gas mixture has more excellent decomposition characteristics than that of pure $\mathrm{C}_{3} \mathrm{~F}_{7} \mathrm{CN}$ at the same condition, which is relatively suitable for use as a gas-insulated medium in electrical equipment.

\section{Conflicts of interest}

There are no conflicts to declare.

\section{Acknowledgements}

The current work is supported by the science and technology project of China Southern Power Grid (No. CSGTRC-K163010)

\section{References}

1 A. Beroual and A. Haddad, Recent Advances in the Quest for a New Insulation Gas with a Low Impact on the Environment to Replace Sulfur Hexafluoride $\left(\mathrm{SF}_{6}\right)$ Gas in High-Voltage Power Network Applications, Energies, 2017, 10(8), 1216.

2 X. Zhang, Y. Li, S. Xiao, et al., Decomposition mechanism of $\mathrm{C}_{5} \mathrm{~F}_{10} \mathrm{O}$ : An environmentally friendly insulation medium, Environ. Sci. Technol., 2017, 51(17), 10127-10136.

3 J. Reilly, R. Prinn, J. Harnisch, et al., Multi-gas assessment of the Kyoto Protocol, Nature, 1999, 401(6753), 549. 
4 Y. Kieffel, T. Irwin, P. Ponchon, et al., Green Gas to Replace $\mathrm{SF}_{6}$ in Electrical Grids, IEEE Power and Energy Magazine, 2016, 14(2), 32-39.

5 M. P. Sulbaek Andersen, M. Kyte, S. T. Andersen, et al., Atmospheric Chemistry of $\left(\mathrm{CF}_{3}\right)_{2} \mathrm{CFCN}$ : A Replacement Compound for the Most Potent Industrial Greenhouse Gas, $\mathrm{SF}_{6}$, Environ. Sci. Technol., 2017, 51(3), 1321-1329.

6 Z. Lv, D. Zhao and S. Xu, Facile synthesis of mesoporous melamine-formaldehyde spheres for carbon dioxide capture, $R S C$ Adv., 2016, 6(64), 59619-59623.

7 J. G. Owens, Greenhouse gas emission reductions through use of a sustainable alternative to $\mathrm{SF}_{6}$, IEEE Electrical Insulation Conference (EIC), Montréal, Canada, 2016, pp. 535-538.

$8 \mathrm{Y}$. Kieffel, Characteristics of g3-an alternative to $\mathrm{SF}_{6}, I E E E$ International Conference on Dielectrics(ICD), Montpellier, France, 2016, vol. 2, pp. 880-884.

9 H. E. Nechmi, A. Beroual, A. Girodet, et al., Fluoronitriles/ $\mathrm{CO}_{2}$ Gas Mixture as Promising Substitute to SF6 for Insulation in High Voltage Applications, IEEE Trans. Dielectr. Electr. Insul., 2016, 23(5), 2587-2593.

10 C. Preve, R. Maladen and D. Piccoz, Method for validation of new eco-friendly insulating gases for medium voltage equipment, IEEE International Conference on Dielectrics (ICD), Montpellier, France, 2016, vol. 1, pp. 235-240.

11 M. P. S. Andersen, M. Kyte, S. T. Andersen, C. J. Nielsen and O. J. Nielsen, Atmospheric Chemistry of $\left(\mathrm{CF}_{3}\right)_{2} \mathrm{CF}-\mathrm{CN}$ : A Replacement Compound for the Most Potent Industrial Greenhouse Gas, $\mathrm{SF}_{6}$, Environ. Sci. Technol., 2017, 51(3), 1321-1329.

12 X. Zhang, Y. Li, S. Xiao, et al., Theoretical study of the decomposition mechanism of environmentally friendly insulating medium $\mathrm{C}_{3} \mathrm{~F}_{7} \mathrm{CN}$ in the presence of $\mathrm{H}_{2} \mathrm{O}$ in a discharge, J. Phys. D: Appl. Phys., 2017, 50(32), 325201.

13 A. C. T. V. Duin, S. Dasgupta, F. Lorant, et al., ReaxFF: A Reactive Force Field for Hydrocarbons, J. Phys. Chem. A, 2001, 105(41), 9396-9409.

14 J. Zhang, Y. Si, C. Leng, et al., Molecular dynamics simulation of $\mathrm{Al}-\mathrm{SiO}_{2}$ sandwich nanostructure melting and low-temperature energetic reaction behavior, RSC $A d v$, 2016, 6(64), 59313-59318.

$15 \mathrm{~S}$. Bhoi, T. Banerjee and K. Mohanty, Insights on the combustion and pyrolysis behavior of three different ranks of coals using reactive molecular dynamics simulation, RSC Adv., 2016, 6(4), 2559-2570.

16 D. Hong, L. Liu, Y. Huang, et al., Chemical effect of $\mathrm{H}_{2} \mathrm{O}$ on $\mathrm{CH}_{4}$ oxidation during combustion in $\mathrm{O}_{2} / \mathrm{H}_{2} \mathrm{O}$ environments, Energy Fuels, 2016, 30(10), 8491-8498.
17 H. J. C. Berendsen, J. P. M. Postma, W. F. V. Gunsteren, et al., Molecular dynamics with coupling to an external bath, $J$. Chem. Phys., 1984, 81(8), 3684-3690.

18 G. Te Velde, F. M. Bickelhaupt, E. J. Baerends, et al., Chemistry with ADF, J. Comput. Chem., 2001, 22(9), 931-967.

19 T. C. Ngo, D. Q. Dao, M. T. Nguyen, et al., A DFT analysis on the radical scavenging activity of oxygenated terpenoids present in the extract of the buds of Cleistocalyx operculatus, RSC Adv., 2017, 7(63), 39686-39698.

20 Q. Zhou, X. Su, W. Ju, et al., Adsorption of H2S on graphane decorated with Fe, Co and Cu: a DFT study, RSC Adv., 2017, 7(50), 31457-31465.

21 P. Zhang, X. Hou, J. Mi, et al., Curvature Effect of SiC Nanotubes and Sheet for $\mathrm{CO}_{2}$ Capture and Reduction, $R S C$ Adv., 2014, 4(90), 48994-48999.

22 Y. Zhao and D. G. Truhlar, The M06 suite of density functionals for main group thermochemistry, thermochemical kinetics, noncovalent interactions, excited states, and transition elements: two new functionals and systematic testing of four M06-class functionals and 12 other functionals, Theoretical Chemistry Accounts: Theory, Computation, and Modeling, 2008, 120(1), 215-241.

23 Y. Zhao and D. G. Truhlar, A new local density functional for main-group thermochemistry, transition metal bonding, thermochemical kinetics, and noncovalent interactions, $J$. Chem. Phys., 2006, 125(19), 194101.

24 A. S. Menon and L. Radom, Consequences of spin contamination in unrestricted calculations on open-shell species: effect of Hartree-Fock and Møller-Plesset contributions in hybrid and double-hybrid density functional theory approaches, J. Phys. Chem. A, 2008, 112(50), 13225-13230.

25 X. Zhang, S. Xiao, J. Zhang, et al., Influence of humidity on the decomposition products and insulating characteristics of $\mathrm{CF}_{3} \mathrm{I}$, IEEE Trans. Dielectr. Electr. Insul., 2016, 23(2), 819828.

$26 \mathrm{R}$. Ono and T. Oda, Measurement of gas temperature and $\mathrm{OH}$ density in the afterglow of pulsed positive corona discharge, J. Phys. D: Appl. Phys., 2008, 41(3), 035204.

27 Y. Fu, M. Rong, K. Yang, et al., Calculated rate constants of the chemical reactions involving the main byproducts $\mathrm{SO}_{2} \mathrm{~F}, \quad \mathrm{SOF}_{2}, \quad \mathrm{SO}_{2} \mathrm{~F}_{2}$ of $\mathrm{SF}_{6}$ decomposition in power equipment, J. Phys. D: Appl. Phys., 2016, 49(15), 155502.

28 H. Tanaka, D. Tanahashi, Y. Baba, et al., Finite-difference time-domain simulation of partial discharges in a gas insulated switchgear, High Voltage, 2016, 1(1), 52-56.

29 Z. Chen, W. Sun and L. Zhao, High-temperature and Highpressure Pyrolysis of Hexadecane: A Molecular Dynamic Simulation Based on Reactive Force Field (ReaxFF), J. Phys. Chem. A, 2017, 121(10), 2069. 